\title{
Langmuir Monolayer Characteristics of Erucylphosphocholine A Novel Anti-Tumor Drug
}

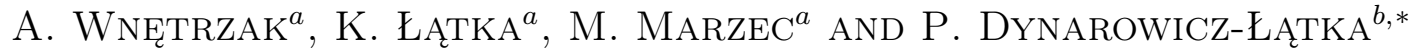 \\ ${ }^{a}$ Institute of Physics, Jagiellonian University, W.S. Reymonta 4, 30-059 Kraków, Poland \\ ${ }^{b}$ Faculty of Chemistry, Jagiellonian University, R. Ingardena 3, 30-060 Kraków, Poland
}

\begin{abstract}
Erucylphosphocholine, an alkylphosphocholine anticancer drug, was employed for Langmuir monolayer characterization and liquid crystalline studies. Differential scanning calorimetry measurements together with texture observation with polarizing microscope revealed the presence of nematic phase. Film forming properties of erucylphosphocholine at the air/water interface were thoroughly investigated by means of surface pressure-area $(\pi-\mathrm{A})$ and electric surface potential-area $(\Delta V-A)$ isotherms. The influence of such factors as subphase temperature, ionic strength, speed of compression, number of molecules spread at the surface on the characteristics of the $\pi-A$ isotherms was investigated. Erucylphosphocholine was found to form very stable Langmuir monolayers, which are almost not influenced by experimental conditions. The liquid character of its monolayers was confirmed with both compressibility modulus values and homogeneous Brewster angle microscopy images.
\end{abstract}

PACS: 68.18.- $\mathrm{g}$

\section{Introduction}

Phospholipids that constitute cell membranes of mammals, i.e. glycerophospholipids (Fig. 1a) and sphingophospholipids, play a very important role in cell function and development, in addition to their structural function and molecular recognition [1]. The replacement of natural phospholipids by their synthetic, structurally modified analogues has resulted in significant changes in cell function. This has been the starting point for a new line of research in the treatment of various diseases. In this way, a new group of substances that are useful as anticancer drugs, known as antitumor lipids (ATLs), has been created. Their synthesis was inspired by the properties found for lysophosphatidylcholines - LPCs (Fig. 1b), which occur in natural membranes as an intermediate product of phosphatidylcholine metabolism [2]. Interestingly these compounds, having detergent activity, were found to cause cell lysis and affect the fluidity and permeability of biological membranes [3, 4]. Taking these properties into account, structural analogues of LPCs were synthesized, in which easily hydrolysable ester bond at the $\mathrm{C} 1$ carbon has been replaced by ether moiety, while the hydroxyl group at the $\mathrm{C} 2$ carbon was esterified with a small alkyl substituent (methyl or ethyl). Such molecules were called alkyl-lysophospholipids - ALPs (Fig. 1c). Although they are structurally similar to LPCs, their stability was significantly improved by the chemical modification. Moreover, due to differences in functional groups,

\footnotetext{
* corresponding author; e-mail: ucdynaro@cyf-kr.edu.pl
}

they are stable in vivo in contrast to natural phospholipids, which can be easily metabolized. Interestingly, ALPs were proved to show cytostatic and cytotoxic activity on certain tumor cells. In addition, these compounds have important biological functions, among which the induction of cell maturation and apoptosis (programmed cell suicide) should be emphasized, in addition to the inhibition of tumor cell invasion [5]. The most effective drug of the ALPs series is edelfosine (1-O-octadecyl-2-O-methyl-rac-glycero-3-phosphocholine, in short Et-18$\left.-\mathrm{OCH}_{3}\right)[6]$.

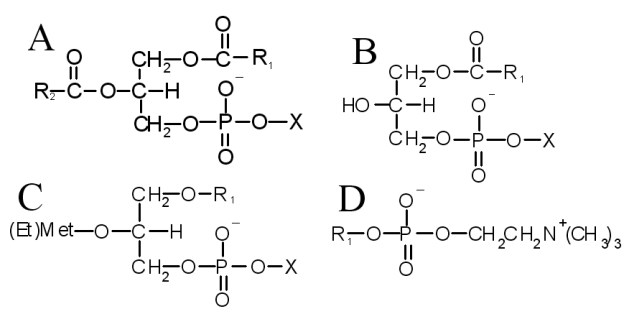

Fig. 1. Chemical formulae of the natural phospholipids and their synthetic analogues. General chemical structure of (A) glycerophospholipid, (B) lysophosphatidylcholine (LPC), (C) alkyl lysophospholipid (ALP), (D) alkylphosphocholine (APC).

In search of new derivatives of simpler chemical structure, exhibiting similar physiological properties as the ALPs, lipid ethers were synthesized, which do not have the glycerol backbone in their structure (Fig. 1d). They were called alkylphosphocholines (APCs). Such a simpli- 
fication of the structure was originated by Eibl and co-workers from the Max Planck Institute in Göttingen [7]. Their research led to synthesis of the first alkylphosphocholine possessing C16 alkyl chain (R1) (Fig. 1d) miltefosine (hexadecylophosphocholine, HePC, C16PC) - [8], which was approved (under the name of Miltex) for the topical treatment of metastatic breast cancer and skin. Another products of this group include its longer homologues — octadecylphosphocholine (OcPC, C18PC), with C18 hydrocarbon tail (R1) and erucylphosphocholine, ErPC (Fig. 2), the latter having 22-carbon hydrocarbon chain and double cis bond between 13 and 14 carbon atoms [9-11].

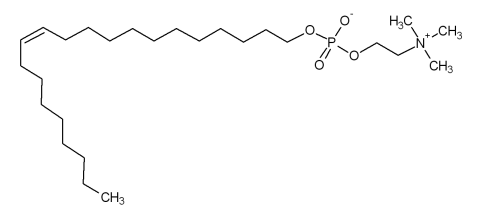

Fig. 2. Chemical structure of erucylphosphocholine (ErPC).

The absence of glycerol unit in the molecule is of great biological importance, since while natural phospholipids are metabolized easily by different phospholipases, such as A1, A2, C and D, the resulting alkyl ether-type molecules are not susceptible to such enzymes. This means significant advantages of these substances when used for the purpose of drugs. Similarly to phospholipids, they are surface-active [12], which results from their amphiphilic character (the presence of two opposing fragments within a molecule - a hydrophobic chain and a hydrophilic group). This property facilitates the affinity of such molecules to biomembranes. Indeed, cellular membrane was assigned to be the primarily site of action for both ALPs and APCs [13, 14], contrary to traditional cytotoxic agents applied in chemotherapy (e.g. cisplatin or vinblastine), which are known to target DNA $[6,15]$.

Apart from many studies, the exact mode of action and the mechanism of selectivity of ATLs are still not clear. In order to get insight into these issues, studies on molecular interactions between the drug and membrane components are of utmost importance. To reach this goal, the Langmuir monolayer technique [16], which serves as a very useful, easy to handle and controllable model of biomembranes [17], can be employed. However, the requirement for using this technique is that the molecule of interest must be surface active and possess the ability of stable Langmuir monolayer formation.

Therefore, the aim of this paper is to check the capability of forming Langmuir monolayers by erucylphosphocholine - one of the newest alkylphosphocholines, having the advantage over $\mathrm{HePC}$ and $\mathrm{OcPC}$ of being suitable for intravenous administration, thus showing improved anticancer activity with reduced hemolytic and gastrointestinal side effects [18]. Anticancer activity of ErPC has already been confirmed both in vivo and in vitro models.
Because ErPC is able to cross blood-brain barrier [10], therefore it can be effectively applied for glioblastoma therapy, inducing apoptosis in chemo- and radiation resistant glioma cell lines $[10,19,20]$. Effective anticancer action of this drug was also confirmed on hepatocellular liver carcinoma cell lines [21], endometrial and ovarian cancer cells [22], lymphoma [9] and leukemia cell lines as well as on methylnitrosurea induced mamma carcinoma of the rat in vivo [23].

Our results confirm that ErPC is capable of stable Langmuir monolayers formation and is a suitable material for subsequent studies with the Langmuir technique. We do expect that further systematic studies on interactions between ErPC and membrane components may be of much help in getting insight into the way how the drug can selectively be targeted to the tumor cell membrane, sparing the normal cells. This will be a subject of our future articles.

\section{Experimental}

Anhydrous erucylphosphocholine was kindly supplied by Aeterna Zentaris GmbH (Frankfurt, Germany). The compound was kept in the freezer in an evacuated dessicator in the presence of anhydrous calcium chloride as a strongly hydroscopic medium. The spreading solution for the Langmuir experiments was prepared by dissolving the investigated compound in a chloroform:methanol (Sigma-Aldrich, p.a.) $(9: 1 \mathrm{v} / \mathrm{v})$ mixture with a typical concentration of $c a .0 .2-0.5 \mathrm{mg} / \mathrm{mL}$. The spreading solution was dropped onto the surface of ultrapure water (produced by a Nanopure water purification system coupled to a Milli-Q water purification system, resistivity = $18.2 \mathrm{M} \Omega \mathrm{cm}$ ) with a Microman Gilson microsyringe, precise to $\pm 0.2 \mu \mathrm{L}$. In routine experiments $4.54 \times 10^{16}$ molecules were spread at the water surface of $\mathrm{pH} 5.6$ and $T=20^{\circ} \mathrm{C}$. The subphase temperature was controlled to within $0.1^{\circ} \mathrm{C}$ by a circulating water system from Julabo. The ionic strength of the subphase was adjusted by addition of $\mathrm{NaCl}$ (Merck, p.a.). To study the influence of subphase $\mathrm{pH}$, the spreading solution was dropped onto the Theorell-Stenhagen buffer subphase [24] (ionic strength $<0.1)$, which was prepared with ultrapure water. The $\mathrm{pH}$ of aqueous subphases was measured with an Elmetron CX-731 pH meter. Experiments were carried out on a Langmuir trough (total area $=600 \mathrm{~cm}^{2}$ ) placed on an antivibration table. Surface pressure was measured with the accuracy of $\pm 0.1 \mathrm{mN} / \mathrm{m}$ using a Wilhelmy plate made from chromatography paper (Whatman Chr1) as the pressure sensor. After spreading, the monolayers were left for $10 \mathrm{~min}$ for the solvent to evaporate, after which compression was initiated with a barrier speed of $50 \mathrm{~cm}^{2} / \mathrm{min}$, unless otherwise specified. The monolayer stability was verified by monitoring the change in area while holding the surface pressure constant. Each isotherm was repeated at least three times to ensure reproducibility of the curves to $\pm 2 \AA^{2}$.

Surface potential measurements were performed with the Kelvin probe (model KP2, NFT, Germany) mounted 
on a NIMA trough. The vibrating plate was located $c a$. $2 \mathrm{~mm}$ above the water surface while the reference electrode, made from platinum foil, was placed in the water subphase. The surface potential measurements were reproducible to $\pm 10 \mathrm{mV}$. Both surface pressure-area and electric surface potential-area isotherms reported here are the averages of at least three experiments.

The Brewster angle microscopy (BAM) experiments were performed with ultraBAM instrument (Accurion $\mathrm{GmbH}$, Goettingen, Germany) equipped with a $50 \mathrm{~mW}$ laser emitting $p$-polarized light at a wavelength of $658 \mathrm{~nm}$, a $10 \times$ magnification objective, polarizer, analyzer and a CCD camera. The spatial resolution of the BAM was $2 \mu \mathrm{m}$.

Differential scanning calorimetry (DSC) measurements were done with Perkin Elmer Diamond 6000 DSC calorimeter. The calorimeter was calibrated by means of the melting points of indium and water. The highly pure nitrogen and helium was used during measurements. The sample was placed in an aluminium pans. The mass of the sample used was equal to $c a .7 \mathrm{mg}$. Three scans (heating and cooling) was done for the compound studied. The heating and cooling rates of all scans were equal to $\pm 10 \mathrm{~K} / \mathrm{min}$.

The polarizing microscope Nikon Eclipse equipped with Linkam heating stage was used for texture observations. The configuration of crossed polarizers was applied. The liquid nitrogen was used to stabilize the heating and cooling rates, which were equal to $\pm 5 \mathrm{~K} / \mathrm{min}$. The texture of the phases appearing during heating and cooling of the sample was registered by the digital camera connected with the microscope. The change in the texture with temperature means change in the phase. Therefore based on the texture observation one can conclude about the transition temperature between the phases detected.

\section{Results and discussion}

The surface pressure-area $(\pi / A)$ isotherm of erucylphosphocholine spread on water $\left(\mathrm{pH} 5.6,20^{\circ} \mathrm{C}\right)$ is shown in Fig. 3, which also contains the compression modulus, $C_{s}^{-1}$ (defined as $C_{s}^{-1}=-A \mathrm{~d} \pi / \mathrm{d} A$ ) vs. surface pressure $(\pi)$ dependence (inset of Fig. 3). The isotherm starts to rise at about $90 \AA^{2} /$ molecule. The course of the isotherm indicates a liquid (L) state of the monolayer. Upon compression, the surface pressure raises monotonically until film collapse, which occurs slightly above $40 \mathrm{mN} / \mathrm{m}$. The state of erucylphosphocholine monolayer can be quantified with the compression modulus values, reaching maximum value of $c a .80 \mathrm{mN} / \mathrm{m}$, which meets the criterion of a liquid character [25]. This is confirmed with homogeneous BAM images throughout the whole compression. From the isotherm it can be seen that the limiting area of the molecule at the surface is ca. $75 \AA^{2}$. This value suggests that the limiting area is determined by the dimension of the molecule head group, i.e. phosphocholine. Such an interpretation can be supported by the fact that the limiting area of other APC homologues differing in the hydrophobic part structure (e.g. hexadecylphosphocholine [26] and octadecylphosphocholine) are very similar to erucylphosphocholine.

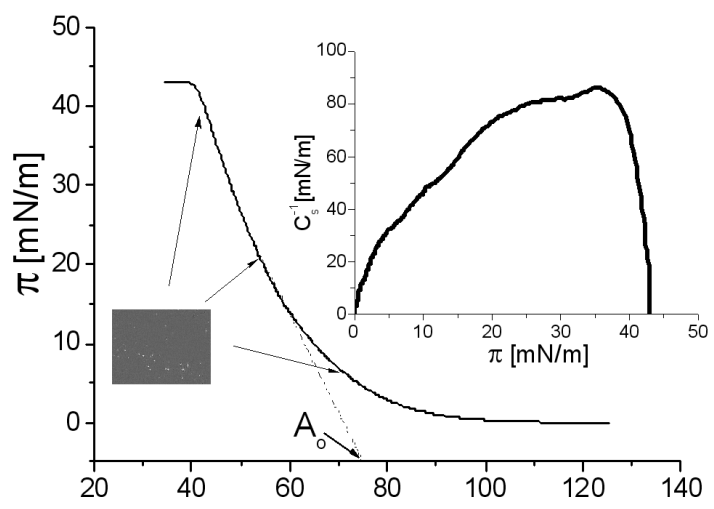

Fig. 3. Surface pressure $(\pi)$-area $(A)$ isotherms of erucylphosphocholine monolayer spread on water together with BAM images. Inset - compression modulus $\left(C_{s}^{-1}\right)-\pi$ dependence. Subphase temperature: $20^{\circ} \mathrm{C}$.

In order to provide a detailed Langmuir monolayer characterization of erucylphosphocholine, monolayer experiments under different subphase conditions were performed, as described below.

In a set of control experiments, we observed that changing the number of molecules deposited on the surface did not influence the isotherms for this compound (see Fig. 4a). Secondly, the variation in compression speed from 50 to $100 \mathrm{~cm}^{2} /$ min does not influence the isotherm, however, with a lower speed of the isotherm $\left(20 \mathrm{~cm}^{2} / \mathrm{min}\right)$ a slight shift is observed towards lower areas (Fig. 4b). This may indicate a partial loss of film-forming molecules from the surface when the compression speed was significantly decreased. Indeed, upon leaving a monolayer on water subphase for 5, 10 or 25 min before the compression was initiated, a small shift towards lower areas is observed upon increasing the time (Fig. 4c), which confirms the previous result.

The influence of subphase temperature on erucylphosphocholine monolayers has also been studied. Figure $4 \mathrm{~d}$ indicates that the change in subphase temperature within the range of $20-30^{\circ} \mathrm{C}$ practically did not alter the isotherms. Only at lower subphase temperature $\left(10^{\circ} \mathrm{C}\right)$ the isotherm is slightly shifted towards smaller areas, however, it is practically parallel to the others recorded at higher temperatures. As a result, the compression modulus-surface pressure curves for all the investigated temperatures superimpose, indicating that the subphase temperature has no effect on monolayer packing. The only parameter that changes with temperature is the collapse pressure - the highest $(43 \mathrm{mN} / \mathrm{m})$ is reached at the lowest investigated temperature, while the lowest $(41 \mathrm{mN} / \mathrm{m})$ at $30^{\circ} \mathrm{C}$.

Figure $4 \mathrm{e}$ shows the isotherms obtained on aqueous subphases of different $\mathrm{pH}$ at $20^{\circ} \mathrm{C}$. As it can be seen, the 


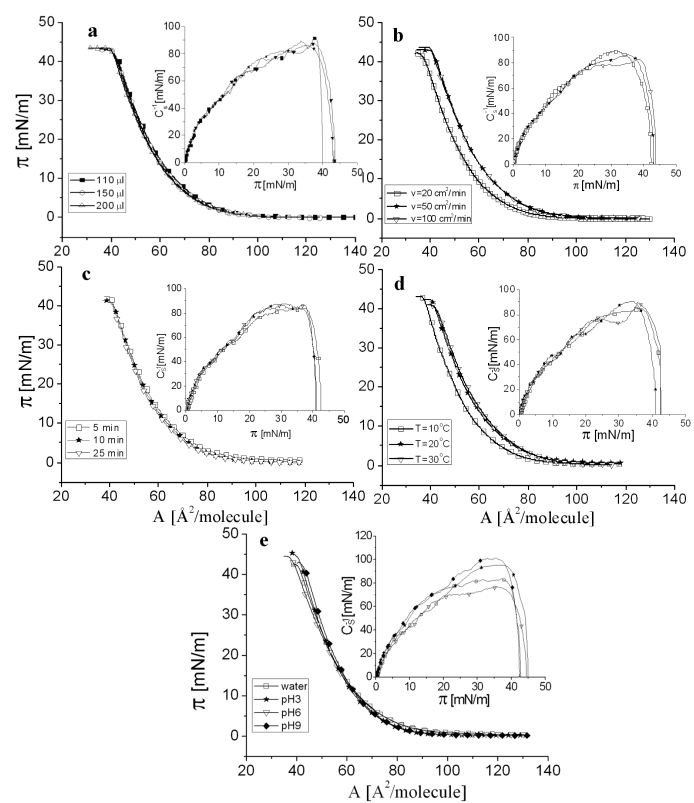

Fig. 4. The influence of experimental conditions on the $\pi$-area isotherms of erucylphosphocholine - description in the text.

change of subphase $\mathrm{pH}$ within the range of 3-9 has practically no influence on the isotherms. This indicates that erucylphosphocholine exists in the form of zwitterions at these $\mathrm{pH}$ values.

From these studies it is evident that changing subphase and compression conditions does not modify significantly the characteristics of monolayers from erucylphoshocholine. Therefore we may conclude that ErPC forms stable Langmuir monolayers at air/aqueous solution interface. To get a further evidence on its stability, the experiment was performed in which the monolayer was first compressed until the desired surface pressure value $(10,20$, and $30 \mathrm{mN} / \mathrm{m})$, which was afterwards kept constant, and the decrease in area was monitored with time (Fig. 5). As it can be seen, no area loss was observed with time, which is another proof of the film stability.

To get insight into the behavior of erucylphosphocholine spread at the air/water interface, the change of surface potential $(\Delta V)$ vs. molecular area was recorded simultaneously with the $\pi-A$ isotherms and the obtained results are presented in Fig. 6. Generally, the surface potential starts to change at slightly larger areas than the surface pressure, which is usually observed for film-forming molecules [27]. Upon compression, the surface potential rises gradually, reaching maximum (of $c a$. $180 \mathrm{mV}$ ), which is achieved at the molecular area similar to that of the film collapse. We have applied the Helmholtz model of a Langmuir monolayer [28] to calculate the apparent dipole moment of erucylphosphocholine at the air/water interface. According to this model,

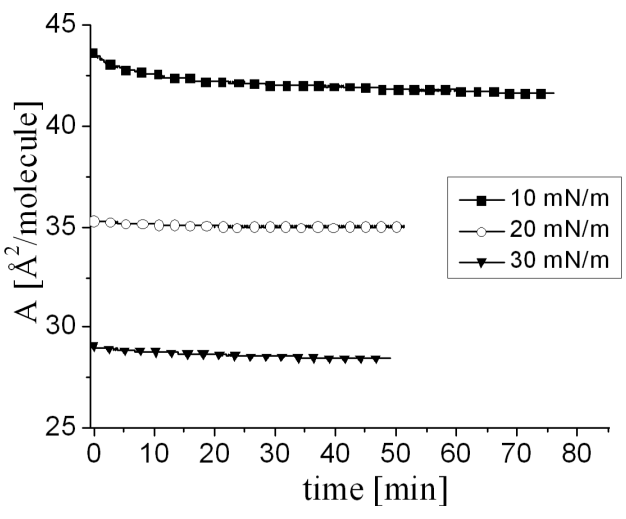

Fig. 5. Static stability experiments of erucylphosphocholine monolayer - description in the text.

$$
\Delta V=\frac{\mu_{\perp}}{A \varepsilon \varepsilon_{0}},
$$

where $\mu_{\perp}$ is the vertical component of the dipole moment (so-called effective dipole moment), $A$ is molecular area, $\varepsilon$ is the electrical permittivity of a monolayer, and $\varepsilon_{0}$ is the electrical permittivity of vacuum. Because $\varepsilon$ values are unknown and are not constant upon film compression [28], therefore so-called apparent dipole moment is introduced and defined as: $\mu_{\mathrm{A}}=\mu_{\perp} / \varepsilon$. The plots of $\mu_{\mathrm{A}}$ vs. molecular area dependences are shown in Fig. 6. Similarly to $\Delta V$, the apparent dipole moment increases upon film compression, reaching a maximum value (of $0.173 \mathrm{D})$ at molecular areas near the film collapse.

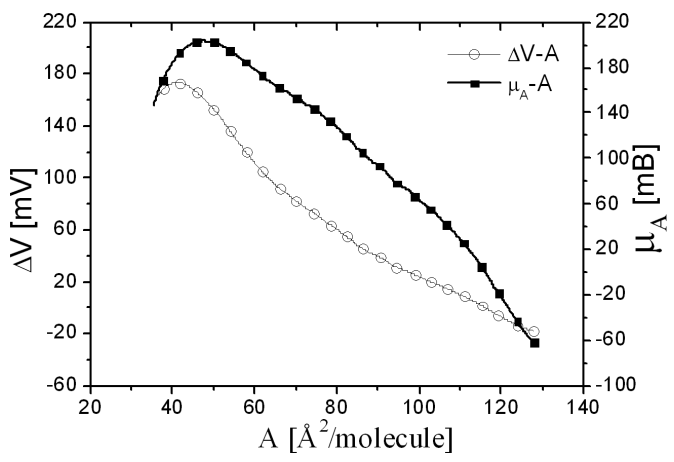

Fig. 6. Electric surface potential $(\Delta V)$ and apparent dipole moment $\left(\mu_{\mathrm{A}}\right)$ for erucylphosphocholine monolayer.

Using polarizing microscope the textures of the thin layer of ErPC were observed. The substance was put between two glass plates and observation of the textures was done at heating and cooling (two scans) with the rate of $5 \mathrm{~K} / \mathrm{min}$. First heating was from $25^{\circ} \mathrm{C}$ to $100^{\circ} \mathrm{C}$ and cooling from $100^{\circ} \mathrm{C}$ to $-50^{\circ} \mathrm{C}$, afterwards the heating between $-50^{\circ} \mathrm{C}$ to $235^{\circ} \mathrm{C}$ and cooling from $235^{\circ} \mathrm{C}$ to $-100^{\circ} \mathrm{C}$ were performed. During the first heating, the first change of the texture has been registered at $63^{\circ} \mathrm{C}$ and the second one at $70^{\circ} \mathrm{C}$. It seems that the first one is related to the transition between two crystalline phases 
(Cr1 and Cr2), while the second one corresponds to the transition from crystal to nematic phase $(\mathrm{N})$. The nematic phase has been observed upon heating up to $100^{\circ} \mathrm{C}$ and on further cooling down to $-0.5^{\circ} \mathrm{C}$ when the transition to Cr2 has been observed. During further cooling, the transition $\mathrm{Cr} 2-\mathrm{Cr} 1$ has been registered at $-23.5^{\circ} \mathrm{C}$ and $\mathrm{Cr} 1$ has been visible up to $-50^{\circ} \mathrm{C}$. The same phases ( Cr1, Cr2 and N) have been observed during second scan of heating and cooling, and the nematic phase has been detected up to $235^{\circ} \mathrm{C}$ when the substance starts to cool down. As an example, textures of $\mathrm{Cr} 1, \mathrm{Cr} 2$ and nematic phases are presented in Fig. 7, both upon heating and cooling.

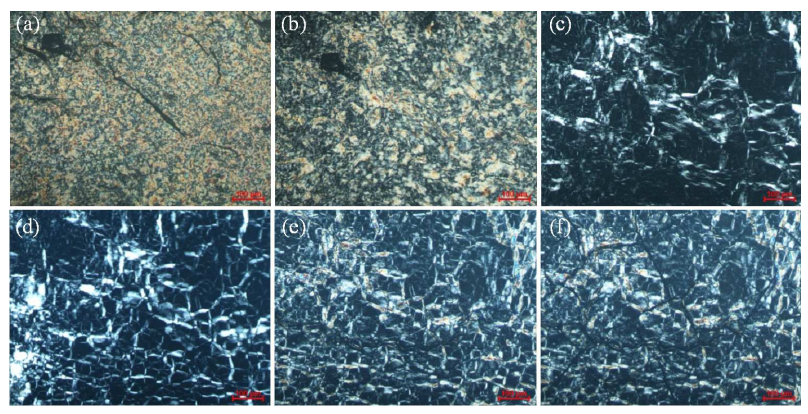

Fig. 7. Textures observed during heating (a-d) and cooling (e-f) at temperatures: $-50^{\circ} \mathrm{C}, \mathrm{Cr} 1$ (a); $60{ }^{\circ} \mathrm{C}$, $\mathrm{Cr} 2(\mathrm{~b}) ; 70^{\circ} \mathrm{C}, \mathrm{N}(\mathrm{c}) ; 235^{\circ} \mathrm{C}, \mathrm{N}(\mathrm{d}) ;-30^{\circ} \mathrm{C}, \mathrm{Cr} 1$ (e); $-66^{\circ} \mathrm{C}, \mathrm{Cr} 2(\mathrm{f})$.

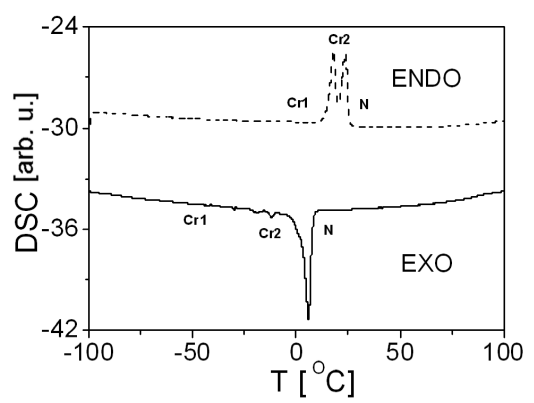

Fig. 8. DSC scans registered with rate of $10 \mathrm{~K} / \mathrm{min}$ for ErPC. Heating - dashed line, cooling - solid line; ENDO - up, EXO — down.

DSC measurements were done in the same way as the texture observation: first heating was performed from room temperature up to $100^{\circ} \mathrm{C}$ and then, after cooling down to $-50^{\circ} \mathrm{C}$, the sample was again heated up to $235^{\circ} \mathrm{C}$. Afterwards it was cooled down to $-100^{\circ} \mathrm{C}$ and heated up again to $235^{\circ} \mathrm{C}$, then cooled to $-100^{\circ} \mathrm{C}$ and next heated to the room temperature. The substance was not heated above $235^{\circ} \mathrm{C}$ to prevent thermal decomposition of the sample.

Figure 8 presents the DSC curves obtained at heating and cooling of the substance studied. As an example, the third of three scans (heating and cooling) is shown. As one can see, one doubled strong peak is visible on the heating curves while on cooling one strong peak and two small anomalies. The description of the recorded anomalies was made on the basis of the above-mentioned texture observations. The transition temperatures as well as transition enthalpies for each peak registered have been calculated using Perkin Elmer Software. The results are gathered in Table.

TABLE I

Transition temperatures and enthalpy changes calculated from DSC measurements.

\begin{tabular}{c|c|c|c}
\hline \hline & Peak & $\begin{array}{c}\text { Onset - transition } \\
\text { temperature }\left[{ }^{\circ} \mathrm{C}\right]\end{array}$ & $\begin{array}{c}\text { Enthalpy change } \\
{[\mathrm{kJ} / \mathrm{mol}]}\end{array}$ \\
\hline \multirow{3}{*}{ heating } & 1 & 15.2 & 13.2 \\
& 2 & 21.4 & 19.0 \\
& 3 & 7.9 & 29.3 \\
cooling & 4 & -10.5 & 0.7 \\
& 5 & -19.3 & 0.4
\end{tabular}

As it is seen from Table, the transition temperatures have been shifted towards lower temperatures during cooling, which is typical for substances exhibiting liquid crystalline properties. Based on DSC and texture observation results, one can conclude that nematic liquid crystalline phase exists during heating as well as cooling of the sample.

\section{Conclusions}

Erucylphosphocholine is an excellent film-forming material, suitable for the Langmuir monolayer investigations. The $\pi-A$ isotherms are hardly influenced by the experimental conditions. Molecules of erucylphosphocholine increase the surface potential of water $(\Delta V$ values are positive). DSC measurements revealed the presence of nematic liquid crystalline phase upon heating and cooling of the sample.

\section{Acknowledgments}

Aeterna Zentaris GmbH (Frankfurt, Germany) is gratefully acknowledged for providing a sample of erucylphosphocholine for investigations. The research was carried out with the equipment (the Langmuir trough, BAM, DSC and polarizing microscope) purchased thanks to the financial support of the European Regional Development Fund in the framework of the Polish Innovation Economy Operational Program (contract no. POIG.02.01.00-12-023/08).

\section{References}

[1] W.E. Berdel, R. Andreesen, P.G. Munder, J.F. Kuto, CRC Press 2, 41 (1985).

[2] C. Long, R. Odavio, E.J. Sargent, Biochem J. 102, 221 (1967). 
[3] A.R. Poole, J.I. Howell, J.A. Lucy, Nature 227, 810 (1970).

[4] D.L. Dick, D.S. Lawrence, Biochemistry 31, 8252 (1992).

[5] G.A. Ruiter, S.F. Zerp, H. Bartelink, Cancer Res. 15, 2457 (1999)

[6] C. Gajate, F. Mollinedo, Curr. Drug Metab. 3, 491 (2002).

[7] C. Unger, E.A.M. Fleer, J. Kötting, W. Neumüller, H. Eibl, Prog. Exp. Tumor Res. 34, 25 (1992).

[8] H. Eibl, C. Unger, Cancer Treat Rev. 17, 233 (1990).

[9] A.H. van der Luit, S.R. Vink, J.B. Klarenbeek, D. Perrissoud, E. Solary, M. Verheij, W.J. Blitterswijk, Mol. Cancer Ther. 6, 2337 (2007).

[10] A. Rübel, R. Handrick, L.H. Lindner, M. Steiger, H. Eibl, W. Budach, C. Belka, V. Jendrossek, Radiat. Oncol. 1, 6 (2006).

[11] S.M. Konstantinov, H. Biel, M.R. Berger, Br. J. Haematol. 107, 365 (1999).

[12] R. Aveyard, R. Haidon, An Introduction to the Principles of Surface Chemistry, Cambridge University Press, London 1973.

[13] G. Arthur, R. Bittman, Biochim. Biophys. Acta 1390, 85 (1988)

[14] V. Jendrossek, R. Handrick, Curr. Med. Chem. Anti-Cancer Agents 3, 343 (2003).

[15] E.E. Kelley, E.J. Modest, C.P. Burns, Biochem. Pharmacol. 22, 2435 (1992)

[16] G.L. Gaines Jr., Insoluble Monolayers at Liquid-Gas Interfaces, Interscience Publishers, New York 1966.
[17] K. Hacc-Wydro, P. Dynarowicz-Łątka, Annales UMCS, Ser. AA (Chemia) 63, 47 (2008).

[18] M.R. Berger, S. Sobottka, S.M. Konstantinov, H. Eibl, Drugs Today 34, 73 (1998).

[19] W. Kugler, B. Erdlenbruch, A. Jünemann, D. Heinemann, H. Eibl, M. Lakomek, J. Neurochem. 82, 1160 (2002)

[20] W. Kugler, F. Bucholtz, F. Köhler, H. Eibl, M. Lakomek, B. Erdlenbruch, Apoptosis 10, 1163 (2005).

[21] M.P. Carraseo, J.M. Jiménez-López, P. Rios-Marco, J.L. Segovia, C. Marco, Br. J. Pharmacol. 160, 355 (2010).

[22] N. Takai, T. Ueda, K. Nasu, H. Narahara, Gynecol. Oncol. 111, 336 (2008).

[23] H. Eibl, P. Hilgard, C. Unger, Alkylphosphocholines: New Drugs in Cancer Therapy, Kargel, Basel 1992.

[24] H. Theorell, E. Stenhagen, Biochem. Z. 299, 417 (1939).

[25] J.T. Davies, E.K. Rideal, Interfacial Phenomena, Academic Press, New York 1963.

[26] I. Rey Gómez-Serranillos, J. Miñones Jr, P. Dynarowicz-Łatka, E. Iribarnegaray, M. Casas, Phys. Chem. Chem. Phys. 6, 1580 (2004).

[27] V.B.P. Leite, A. Cavalli, O.N. Oliveira, Jr., Phys. Rev. E. 57, 6835 (1998).

[28] O.N. Oliveira, Jr., D.M. Taylor, H. Morgan, Thin Solid Films 7, 210 (1992). 